\title{
O processo da revelação: um caso de incesto
}

Cristina Nunes*

\section{RESUMO}

O incesto é um problema de saúde pública pouco consciencializado pela sociedade; existe, em particular, um elevado subdiagnóstico pelos serviços de saúde. É um dos crimes menos denunciados e mais impunes e a revelação pela vítima é fundamental, embora rara e difícil. 0 médico de família encontra-se numa posição privilegiada para a sua abordagem.

Juno, 39 anos, criada pela família adotiva dos 6 meses aos 7 anos de idade e que, mantendo contacto com a família biológica, é vítima de incesto pelo irmão mais velho até aos 17 anos de idade. Após anos de seguimento clínico, descreve-se o processo moroso da revelação, associado a questões éticas e legais. A doente manifesta personalidade estado-limite, perturbação de stresse pós-traumático, disfunção familiar e social.

O processo terapêutico deve ser prolongado, multidisciplinar e abrangente (individual e familiar). A atitude do médico de família pode favorecer o tratamento pela sua atitude empática e por permitir o reconhecimento pela doente de que as suas emoções mal adaptativas da atualidade foram, no passado, uma resposta de sobrevivência ao incesto.

Palavras-chave: Incesto; Violência.

\section{INTRODUÇÃO}

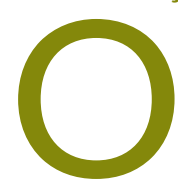

incesto constitui uma das formas mais graves de violência contra as crianças. As consequências do abuso sexual são devastadoras, provocando na maioria perturbações psicológicas graves para toda a vida, inferior desempenho escolar, dificuldades relacionais, por vezes incluindo alterações físicas. ${ }^{1}$ Está associado a consumo de substâncias psicoativas, delinquência e prostituição, com impactos adicionalmente mais negativos. ${ }^{2} \mathrm{O}$ incesto é um tipo agravado de abuso, sendo o agressor alguém da confiança da vítima. É um crime universal, pois o tabu do incesto existe no seio dos mais variados grupos populacionais.

Este tipo de violência constitui um problema de saúde pública. Estudos efetuados em diversas regiões mundiais revelam uma taxa de prevalência média de abuso sexual ao longo da vida de $20 \%$ nas mulheres e $7,5 \%$ nos homens. ${ }^{3-4} \mathrm{O}$ autor destes abusos é um conhecido em $2 / 3$ dos casos e, destes, $1 / 3$ é um familiar. ${ }^{5}$ Um dos estudos de prevalência em Portugal revela que $3,7 \%$ de crianças do género masculino e $9,9 \%$ das crianças do género feminino foram vítimas de abuso sexual. ${ }^{6}$ Isto

*Médica Assistente de Medicina Geral e Familiar da UCSP Buraca - ACES Amadora significa que se um ficheiro de utentes for constituído por 400 crianças e jovens, quando estes chegarem aos 18 anos de idade, 15 rapazes e 40 raparigas terão sido vítimas de abuso sexual, em algum momento da sua vida, 41 por um conhecido, entre os quais 25 por um familiar.

Em Portugal, o problema dos maus tratos a crianças e jovens encontra-se legislado desde $1999^{7}$ e, no campo da saúde, tem o apoio de programas de intervenção desde $2007 .{ }^{8}$ Carece, porém, de consciencialização por todos os profissionais. Em 2012, de todos os casos de maus tratos denunciados à Comissão de Proteção de Crianças e Jovens (CPCJ), 2,2\% foram-no por abuso sexual $(n=1525)$ e, destes, apenas $6,7 \%$ foram sinalizados por estabelecimentos de saúde. ${ }^{9}$

No processo de identificação do incesto, a revelação pela vítima é fundamental. No entanto, o segredo é a norma, dadas as características de impermeabilidade do agressor e da família e de negligência da sociedade (a quebra do tabu do incesto é percecionada com horror e é quase inconcebível), tratando-se de um dos crimes menos denunciados.

Quando acontece a revelação deve ser sempre acolhida e tomadas as diligências necessárias para que o abuso não seja perpetrado ou agravado, sobretudo 
quando o agressor permanece na família. Esta ocorrência é comum, já que o índice de condenação é de apenas cerca de $5 \%$, configurando um dos crimes associados a maior impunidade. ${ }^{2}$

Este artigo tem por objetivo reconhecer o incesto como um problema de saúde pública, cujo diagnóstico é raro. O médico de família (MF) encontra-se numa posição privilegiada para o identificar, conseguindo ser uma figura de confiança da vítima para desencadear os mecanismos específicos e estruturados de apoio necessários para promover o seu bem-estar.

\section{DESCRIÇÃO DO CASO}

\section{(os nomes são fictícios)}

Juno, 39 anos de idade, caucasiana, nasceu e reside no distrito de Lisboa, tendo sido criada pelas famílias biológica e adotiva em alternância. Casada desde 2008, pertence a uma família reconstruída, formada pelo cônjuge, dois enteados de 15 e 12 anos (provenientes de casamento anterior do cônjuge) e pela filha comum de 4 anos (Figura 1). A sua mãe e avó adotivas residem no andar superior do mesmo prédio. A irmã adotiva mora na vizinhança. Tem o $9^{\circ}$ ano de escolaridade, que completou numa escola noturna aos 17 anos de idade. É co-sócia de um estabelecimento comercial, onde exerce a sua atividade laboral desde os 16 anos. Trabalha junto da mãe adotiva.

Tem história de episódios depressivos e ansiedade, rinossinusite de tipo alérgico e síndroma do cólon irritável que cursa com períodos de obstipação. Nega outras cirurgias ou internamentos. Nega alergias ou restrições alimentares. Plano nacional de vacinação atualizado. Fumadora até 2008 (18UMA), sem outros consumos de abuso.

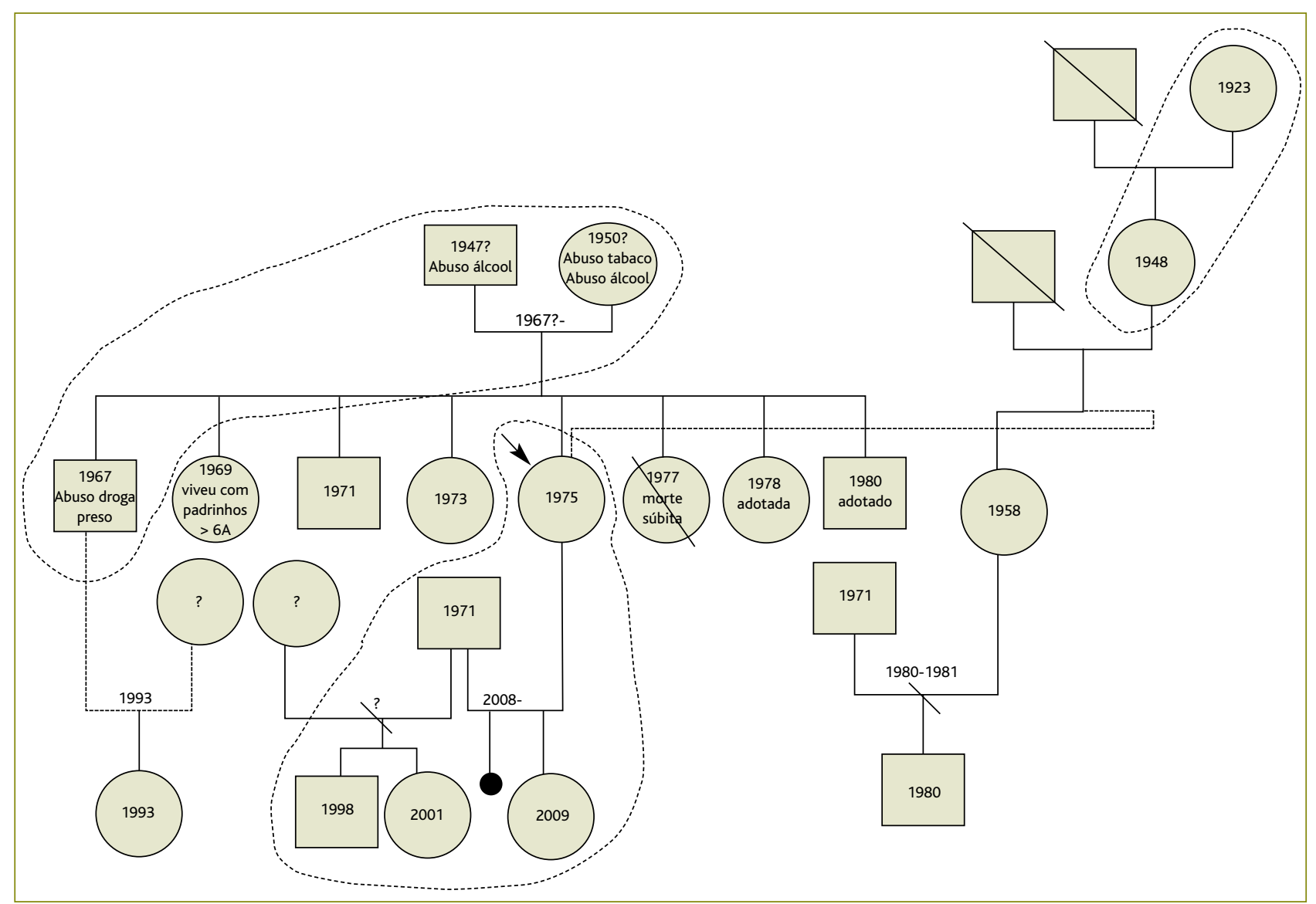

Figura 1. Genograma (2009). Seta: Juno. Linhas a tracejado representam os agregados familiares atuais: família biológica, de Juno e adotiva. 
Menarca aos 17 anos, menstruações regulares. IO:1011, um aborto espontâneo aos 32 anos; gravidez desejada e vigiada, de baixo risco; parto de termo por cesariana em 2009, sem complicações, dando origem a um recém-nascido saudável.

\section{9}

O seguimento com o médico atual foi iniciado em 2009, através da vigilância regular da sua última gravidez. O seguimento da criança foi efetuado por pediatra privado, sem referência a doenças importantes. Foi amamentada até aos 11 meses de idade. Dois meses após o parto, Juno iniciou uma pílula progestativa contínua, peros.

Foi efetuado genograma (Figura 1), onde se destaca fratria numerosa, oito irmãos, cujos dois irmãos mais novos foram "dados para adoção" (sic). A utente refere que a família era muito pobre e a mãe não conseguia cuidar de todos. Nos primeiros anos, a família biológica morou num apartamento exíguo, apenas com dois quartos, um para os pais e outro para os irmãos. Em "bebé", Juno foi apadrinhada por uma vizinha, Horácia, pessoa que começou a designar de "mãe" e com quem passou a viver. Passou a viver ainda com Íris, a sua irmã adotiva, e com a sua avó adotiva.

\section{1-2012}

Após o parto da sua filha, Juno recorreu à consulta da sua médica de família duas vezes (em janeiro de 2011 e em junho de 2012), tendo-lhe sido diagnosticada uma perturbação da ansiedade, medicada na altura com alprazolam.

Sem outras intercorrências médicas de registo durante este período.

\section{3}

\section{2 de agosto de 2013}

(Juno vem acompanhada pela filha)

Subjetivo/Objetivo (SO): Refere nervosismo e irritabilidade agravados e insónia. Sente que sempre foi explorada por Horácia e que não lhe pretende dar mais apoio, pois considera que é de Íris essa obrigação, depois de Juno o ter feito ao longo da vida. Está a trabalhar a tempo inteiro e tem a própria família para cuidar. Revela que terá sido vítima de incesto pelo irmão mais velho. Diz que "mais ninguém sabe". Revelou o in- cesto a Horácia quando tinha 25 anos e nessa altura procurou o apoio de uma psicóloga.

Avaliação (A): Acontecimento violento (Z25). Somatização (P75).

Plano (P): É medicada com venlafaxina $37,5 \mathrm{mg}$ ao pequeno-almoço e alprazolam $1 \mathrm{mg}$ ao deitar e sugerida remarcação de consulta para dentro de 4 a 5 semanas. Indisponível para consultas de psicologia.

\section{2 de setembro de 2013}

SO: Juno vem por manutenção dos sintomas. Vem com a filha e pede-lhe que fique a desenhar numa mesa no outro extremo da sala.

A presença constante de Horácia provoca-lhe uma grande tensão no trabalho (já não a trata por mãe). Tem dificuldade em tomar conta dos enteados, são desarrumados e não lhe obedecem.

Em relação ao incesto refere que foi perpetrado dos 5 aos 17 anos de idade, no início tinha o irmão 11-12 anos. Foi viver com a família adotiva meses depois de nascer e até aos 7 anos de idade, mas passava alguns fins-de-semana com os pais. Horácia "devolveu-a" à família de origem aos 7 anos de idade quando não pôde mais tomar conta dela. Tem uma visão confusa e enublada dos acontecimentos: "não sei bem a data que saí de casa".

A sua relação com o pai era boa, mas escassa: "Sempre me dei bem com ele. O meu pai trabalhava muito, fazia turnos e muitas noites." A sua relação com a mãe de origem, Cibele, era conflituosa: "a minha mãe batia-me muito. Houve um ano em que ela tomou conta de crianças; punha-as em fila e dava-lhes bofetadas sem parar. Depois também eu lhes batia e lhes puxava os cabelos“. Recorda que a mãe passava os dias todos fora de casa, no café. Quem a ia buscar à escola era o irmão mais velho. O irmão era "normal" (sic). Esteve preso por pequenos furtos, de rádios e, por vezes, fumava. Quando questionada sobre os seus sentimentos em relação ao irmão, diz que nunca gostou dele, mas não o quer condenar. O incesto acontecia de dia, com os outros irmãos na escola e os pais ausentes. E acrescenta: "Eu não podia deixar a porta do quarto fechada, nem trazer amigos".

Refere que a família biológica retornou à sua terra $\mathrm{e}$ por isso não os tem visto, mas já lá foi. Falou com o irmão e também com a mãe que lhe disse: "O que é que 
isso interessa agora? Já são coisas do passado!” Juno não revelou ao pai, porque "se ele soubesse, era capaz de o matar".

A: Problema relacional (Z20).

P: Ajuste da terapêutica: venlafaxina passou a $75 \mathrm{mg}$ e alprazolam duas vezes por dia.

\section{Outubro 2013 - consulta com a mãe adotiva de Juno}

A D. Horácia deambula com dificuldade, apoiada em canadianas, após uma cirurgia ortopédica complicada com septicémia. Refere estar muito preocupada com a filha adotiva. "Ela parece estar muito doente: perdeu peso, vomita e bate-se a ela própria. Enerva-se com os enteados e até mesmo com as clientes! Parece obcecada com as limpezas." Refere tristeza e anedonia devido a mudanças em Juno. "Já não é a mesma... Quando lhe pedi para ir ajudar a avó, disse que não era minha criada. Afastou-se muito ultimamente."

Quando questionada, refere os principais acontecimentos da sua vida (Quadro I). Diz que Juno na escola primária "não se deu bem com o professor", pois a menina era "rebelde". Nas férias "achava-a diferente das outras raparigas... Na praia não se despia, era muito séria". Em conversas de jovens, Juno evitava ao máximo

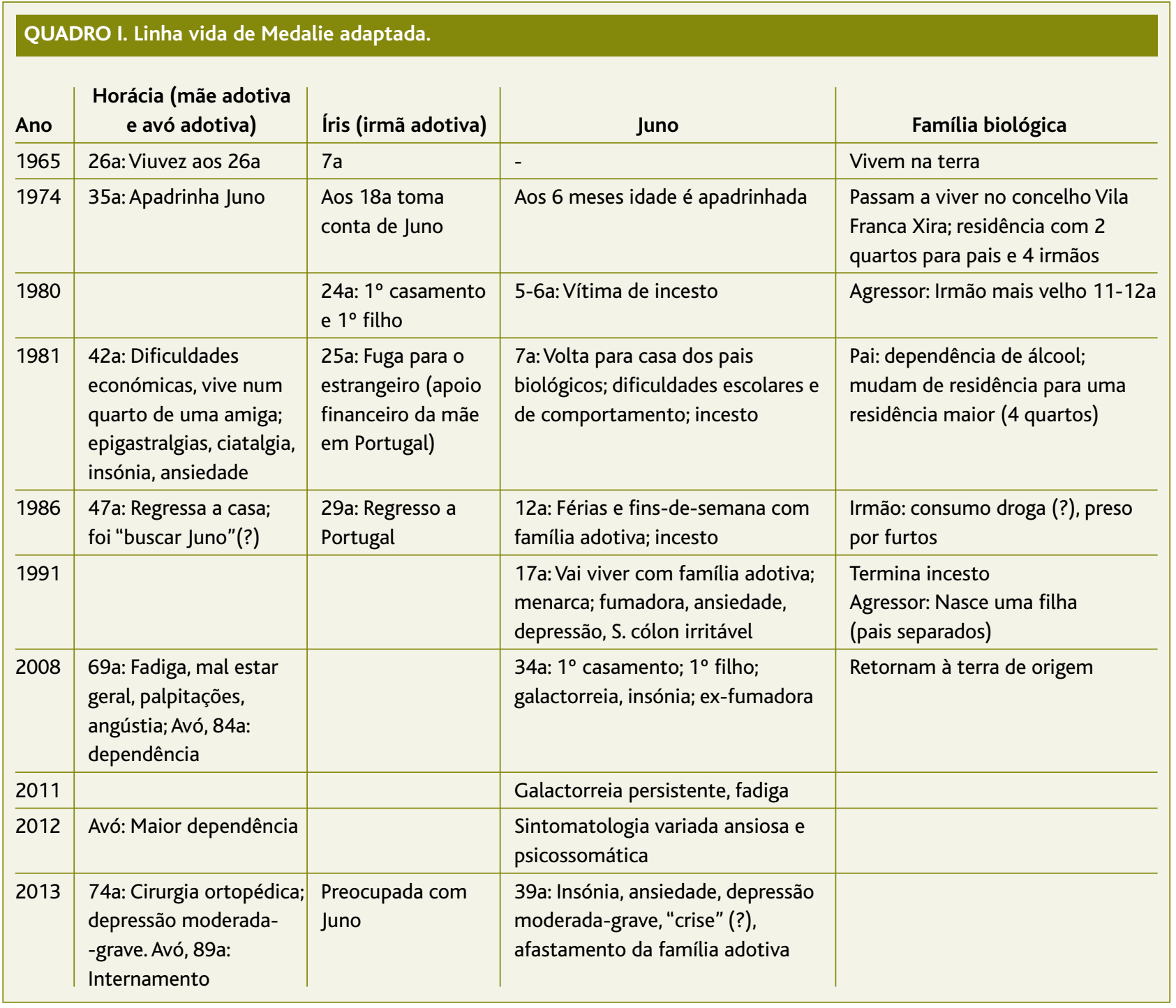


falar sobre sexualidade. Dizia: “Que horror!”. Em casa ou no trabalho Juno manifestava uma irritabilidade intensa, por vezes incompreensível. Com as amigas era muito brusca e tinha frequentes "ataques de ciúmes". Se uma amiga começava a falar com outra que não ela, Juno "fazia cortes radicais" das amizades.

Por volta dos 12 anos (?), Juno regressou à casa adotiva, mantendo visitas à família biológica que residia num $7^{\circ}$ andar sem elevador. Para que Horácia não tivesse que subir, era sempre este irmão quem aparecia à porta da rua do prédio e subia com a menina. Mais tarde completou o $9^{\circ}$ ano à noite e começou a colaborar no cabeleireiro.

Para Horácia, o pai de Juno era "uma pessoa simples e agradável". Apresentava sinais de "alcoolismo", (sic), depois de esta filha nascer. A mãe de Juno também "era boa pessoa", sempre alegre, gostava de conversar "com um petisco e uma cerveja"; era, contudo, "desleixada, não ligava aos filhos e tinha a casa muito suja”. Soube que o irmão mais velho de Juno esteve preso, "talvez por droga" (sic).

\section{3 de novembro de 2013}

(Juno vem com marido e filha, por convocação pelo MF)

SO: Refere não ter vindo mais cedo porque fica muito perturbada de falar no passado. Para agravar, existe a tensão com a família adotiva. Horácia procura pela neta, mas a posição do casal é de afastamento.

Sobre o percurso escolar refere que, na altura, não lhe interessava, motivo porque só completou o $6^{\circ}$ ano de escolaridade no tempo "certo". Havia algum absentismo escolar e agressões pelos educadores, mas Juno não se considerava rebelde. O professor da primária tinha um ponteiro com que a agredia por não estar atenta. Aos 7 anos teve outra professora que lhe perguntava a tabuada e, cada vez que não conseguia enunciá-la, levava reguadas. Na escola tinha poucas amigas. Só aos 17-18 anos regressou definitivamente para a família adotiva. Até aí, o contacto era intermitente, aos fins-de-semana, nos períodos de férias e durante alguns meses, altura em que completou o $9^{\circ}$ ano numa escola noturna e trabalhou no cabeleireiro de Horácia.

A: Acontecimento violento (Z25).

P: É reproposto o seguimento em consultas de psicologia, que a doente recusa, pois já fez psicoterapia por longos meses e de momento não está disponível. Pen- sa que não se justifica o envio para psiquiatria.

\section{2 de dezembro de 2013}

SO: Após convocatória, recorre novamente à consulta, acompanhada pelo marido e pela filha. Nas vésperas da consulta é incapaz de dormir e toma seis comprimidos de alprazolam, com fracos resultados. Anda ansiosa e impaciente desde há longa data, agora pior. Revive muitas vezes os acontecimentos traumáticos. Nega pânico e agorafobia. Por vezes grita com a filha e quer isolar-se. Tem ideação suicida, sem intencionalidade.

O marido concorda que, por vezes, é difícil compreender porque Juno se irrita. Como casal mantêm uma boa relação de confiança, mas sente que Juno é instável a nível emocional. Revela que desde há longa data Juno tem episódios de vómitos, por vezes diários e em períodos de stresse. Concordam que lhe tem dado o apoio necessário.

Quando questionada sobre os seus relacionamentos amorosos, Juno refere que teve alguns namorados de curta duração e, mais tarde, por volta dos 18 anos, um mais duradouro e significativo com um vizinho.

Relativamente às rotinas da família biológica, refere que tinha poucas regras; por exemplo, todos jantavam à mesa e tinham horas para ir para a cama, mas não se preocupavam com os deveres da escola nem com as tarefas domésticas. Ainda antes dela, a irmã mais velha também foi vítima de abuso sexual por parte deste irmão, mas ele preferia Juno, para além de que a irmã passou a ser cuidada por uma vizinha. Quando brincava sozinha com os bonecos da Barbie e do Ken era a "fazerem sexo" (sic).

Os abusos continuaram mesmo depois de passar a morar com a família adotiva, pois Horácia trazia-a a cada da família biológica para passar o fim de semana. O irmão ameaçava-a com uma faca que levava sempre para o quarto. Na altura pareceu-lhe ser "assim", nunca se questionou sobre o sucedido. Mesmo quando o irmão "arranjou uma namorada", ele ia ter com Juno. Um destes relacionamentos do irmão deu origem a uma filha. Juno está agitada e, a seu pedido, a consulta termina. O marido não compreende a importância de recontar o incesto.

Entretanto, a filha ficou a desenhar a família num círculo de Thrower (a menina não cedeu o desenho para 
publicação). O símbolo circular que representou a face do pai encontrava-se no meio do papel, desenhado com orelhas e olhos proeminentes, a filha no canto superior direito da folha, a mãe na outra extremidade inferior esquerda representada por um símbolo circular mais pequeno, com os olhos fechados. Durante as consultas, quando a mãe parecia mais ansiosa, a menina vinha para o seu colo e dava-lhe um abraço.

A: Perturbação da personalidade - estado-limite (P80). Stresse pós-traumático (P82). Fator de risco para disfunção familiar e perpetuação de violência (A23).

$\mathrm{P}$ : Concordou-se com o envio para as entidades competentes. Programar consulta periodicamente.

\section{Janeiro 2014}

Realizou-se consultadoria com uma psicóloga do Agrupamento de Centros de Saúde, tendo sido concordado o reencaminhamento do caso para o Núcleo de apoio contra a violência doméstica da área (NAVD) e para o NACJ, tendo em conta o potencial risco para outras crianças e eventuais filhos.

\section{COMENTÁRIO}

\section{O caso - Fatores de risco e consequências}

Muito embora o incesto ocorra em qualquer nível socioeconómico, este caso surgiu numa família pertencente à classe baixa. Os fatores de risco ${ }^{11}$ encontrados neste caso foram: pais jovens com baixo nível de instrução, mãe com fraca autoestima, provável ausência de cuidados contracetivos com gravidezes não desejadas, família numerosa, condições socioeconómicas desfavoráveis, mudança recente de residência e desenraizamento social, quatro crianças retiradas das responsabilidades parentais, irmão preso, pai e mãe prolongadamente distantes da residência, casa descuidada. Família com ligação a consumo de álcool e provável ligação a drogas ilícitas.

Trata-se de uma família incestogénica, ${ }^{12}$ com pais ausentes, mãe desinteressada e negligente e irmão mais velho dominador. Em relação ao padrão de funcionamento é uma família dispersa, com relações internas distantes, onde os seus membros funcionam em pseudoautonomia sem as habituais barreiras e regras, que aqui são pouco claras ou inexistentes. É uma família desorganizada, permeável a relações exteriores, mas pouco estruturantes. Na ausência dos pais, o irmão assu- miu o papel de pai e a filha o papel de mãe, quer a nível organizacional quer a nível sexual.

Foi esta família que constituiu o grupo de vinculação e de referência mais próximo da vítima onde, à sua maneira, se providenciou proteção, educação e afeto. Por outro lado, tratou-se de um grupo fechado e abandonado, que isolou a criança, onde o agressor pôde exercer o seu poder com uma autoridade inquestionável. Houve incapacidade de se conseguir criar um apoio sustentado a esta família, em grande parte dificultado pelas sucessivas mudanças de residência, mas também por uma conspiração do silêncio coletiva, nomeadamente sem o apoio materno.

Os agressores não procuram acabar com os abusos por sua iniciativa. Regra geral, aceitam as práticas abusivas como justificadas. ${ }^{15}$ Os agressores assumem um comportamento semelhante daquele que ocorre por dependência de uma substância. Ficam progressivamente mais agressivos e violentos e cada vez mais possessivos por medo de perder a vítima para outros. ${ }^{14}$ Deste modo, o segredo foi silenciado sob coerção e ameaças contra a vida com arma branca, interferência nos relacionamentos de Juno e o abuso foi normalizado.

O incesto entre irmão mais velho e irmã mais nova é a forma de violência sexual intrafamiliar mais frequente, apesar dos casos entre pai para filha serem os mais denunciados. ${ }^{13} \mathrm{O}$ irmão, 8 anos mais velho do que a vítima, sendo o mais velho da fratria, configurou-se a nível cultural como o primeiro representante do pai. Foi então bastante aceitável para a sociedade este irmão procurar estar sempre perto das irmãs mais novas. ${ }^{13} \mathrm{O}$ jovem apresentava um fraco controlo de impulsos, tendo sido o autor do incesto, o autor de furtos e possivelmente consumidor de drogas "leves". Também ele poderá ter sido vítima de abusos.

No período escolar, Juno foi múltipla vítima de agressões: pelo irmão, pela mãe, pela ausência do pai e pelos professores na escola, aqueles que constituíam as suas referências principais. Consequentemente, durante a infância, revelou grandes dificuldades de rendimento escolar e de comportamento, tornando-se também ela agressora para com outras crianças. Tardiamente completou o $9^{\circ}$ ano, mas com potencialidades cognitivas aparentemente superiores (na atualidade organiza uma família complexa e gere um estabelecimento aberto ao público desde há alguns anos). 
Juno manifestou elevados índices de ansiedade, muito agravados após a doença de Horácia. Revelou características de perturbação de stresse pós-traumático e traços de personalidade estado-limite (DSM V). ${ }^{15} \mathrm{~A}$ literatura mostra que $40-71 \%$ dos doentes com perturbação estado-limite relatam terem sido vítimas de violência sexual; significa que diagnosticar este tipo de personalidade poderá colocar o MF na pista de abusos sexuais. ${ }^{16}$

A família atual apoia Juno, porém, apresenta alguma disfuncionalidade. Revela ainda dificuldades relacionais e sociais com amigas e clientes.

Muito embora a idade e o distanciamento dos eventos traumáticos atenuem os sintomas, o percurso terapêutico é habitualmente prolongado e dispendioso e, assim, o prognóstico será reservado.

\section{O PROCESSO DE DIAGNÓSTICO - REVELAÇÃO E ABORDAGEM}

Revelação

Este caso relata o processo prolongado e complexo da revelação de um caso de incesto. Decorreram várias consultas antes que a utente ganhasse confiança e sentisse disponibilidade do profissional para revelar o seu segredo mais íntimo. Juno foi observando a atitude do médico e desafiando-o em diferentes situações.

Outro aspeto que concorreu para precipitar a revelação foi o aumento das responsabilidades da doente. Estas estiveram na origem do agravamento de sintomas de ansiedade e da maior necessidade em procurar ajuda.

Este caso é demonstrativo do que sucede na maioria destas situações: o incesto permanece na esfera privada e a revelação não acontece durante a infância e adolescência. A revelação é ansiada, mas é tão difícil que apenas na adultícia a capacidade cognitiva e o distanciamento emocional desta paciente permitiram 0 enfrentamento da realidade no seu contexto social. Primeiro contactou a mãe biológica que a aconselhou a procurar uma psicóloga. Depois contou ao marido e, por fim, ao médico de família. Ainda assim, a doente necessitou da presença de um elo securizante nas consultas, fazendo-se acompanhar sempre de um familiar.

\section{Abordagem clínica}

O quadro clínico aparentou ter uma etiologia predominantemente funcional, em concordância com as ideias da doente: queixas variadas, inespecíficas, crónicas, num contexto sociofamiliar desfavorável, bem como uma avaliação geral negativa para patologia orgânica. A galactorreia residual após suspensão da amamentação enquadra-se no quadro funcional. A abordagem médica foi, assim, de escuta num primeiro tempo e menos "medicalizada".

Os instrumentos de avaliação familiar utilizados na fase pré-revelação foram o genograma e o apgar familiar. Já nesta fase se compreendeu que existiam aspetos pouco habituais no passado da doente e que só por si poderiam justificar a sintomatologia crónica. O genograma ou a história clínica não faziam suspeitar de que poderia haver algo mais. Na fase pós-revelação foi realizada a linha de vida de Medalie (Quadro I) que mostrou uma evidente correlação entre as queixas da doente e os acontecimentos de vida. Solicitou-se um círculo de Thrower à filha da vítima, que revelou alguma disfuncionalidade da família atual. Outros membros da família foram inquiridos, aproveitando o facto de pertencerem à mesma lista de utentes. Obteve-se, assim, uma reconstrução mais fidedigna e uma compreensão mais alargada dos acontecimentos da infância de Juno. Compreensivelmente, a recolha de alguns detalhes, carregados de emoções, foi muito incompleta.

Na consulta, a abordagem terapêutica passou pela tentativa constante de manter a confiança da doente e da família, o que se processou com grande dificuldade. Para trabalhar o sentimento de culpa revelado, sensibilizou-se a utente para consultas de psicologia/psiquiatria. A utilização de medidas não farmacológicas de suporte, o uso de benzodiazepinas e de um antidepressivo não surtiram efeito. A doente pareceu encontrar algum alívio com o afastamento das famílias biológica e adotiva.

O médico vivenciou um problema marcado pela violência, sensível e desgastante e para o qual não estava preparado, tendo efetuado pesquisas bibliográficas e promovido discussões interpares e interdisciplinares. Perante a não melhoria clínica e por se tratar de uma situação específica e complexa, num segundo tempo foi efetuada a referenciação para o NVD e para o NPCJ.

\section{Plano de atuação}

Nas diferentes áreas de prevenção, o MF pode intervir: 
1. Ao nível da prevenção primária, de acordo com uma revisão sistemática, ${ }^{17}$ existem várias intervenções que previnem o abuso de crianças: deteção de fatores de risco, questionamento sistemático sobre violência física, psicológica ou sexual, educação parental, educação para a saúde, promoção do desenvolvimento de competências sociais e a ampliação de redes sociais. A única intervenção que demonstrou eficácia foi um programa intensivo de visitações domiciliárias, efetuado por enfermeiras, com início na gravidez e que se prolongaram durante os primeiros anos de vida. Contudo, as restantes intervenções são recomendadas por grupos de peritos.

Assim:

- A família atual de Juno deve ser acompanhada e o MF deve estar alerta para a manifestação de fenómenos menos funcionais no seio familiar, tendo em conta que o indivíduo mais agredido é aquele que tem maior propensão para a transmissão intergeracional de violência. ${ }^{18}$

- Na consulta, o MF procurará usar sempre uma atitude não crítica, de escuta e abertura, o que poderá favorecer a revelação até mesmo de um membro desta família. Existem estudos descrevendo as respostas profissionais que mais favorecem a confiança e a revelação por parte da vítima. São as respostas de compreensão, de apoio, de não dúvida e de ter sido considerado um assunto sério. As respostas contrárias a estas e as expressões de choque e surpresa foram desfavoráveis ao processo de revelação. ${ }^{19-20}$

- Promoção de contactos sociais, como amigos, família e membros da comunidade.

2. Os objetivos primordiais da prevenção secundária e terciária são de identificar e corrigir as sequelas do trauma. O MF permitirá uma continuidade de cuidados e em articulação, essencial para o desenvolvimento do processo terapêutico que será sempre de longa duração.

- É necessário ter em conta que os traços de personalidade da doente surgirão também na relação médico-doente: poderá ser uma interação difícil, onde irão ser testados os limites. Poderão alternar-se períodos de idealização ("o profissional é o único que o percebe") com desvalorização ("o médico não entende nada disto"). A doente pode mostrar grande sensibilidade a pequenas rejeições, como atrasos na consulta ou quando o MF solicita a opinião de um familiar e que serão sentidas como uma quebra do sigilo e uma quebra da confiança.

- Marcação regular de consultas nos CSP. Perante períodos prolongados de ausência, alguns dos contactos poderão ser de iniciativa médica.

- Os motivos de consulta deverão ser analisados à luz deste passado, evitando sobreavaliar ou sobremedicalizar.

- Podem ser detalhados alguns pontos da história clínica ou atual e perceber melhor as consequências da vitimização (perturbações do tipo dissociativo, disfunções sexuais, fenómenos psicossomáticos, etc.).

- Deverão ser reforçados os sucessos em termos de funcionalidade individual e social.

- Deve promover-se a discussão com a doente sobre a sua colaboração com o NVD/ NPCJ, posto que já aceitou a notificação pelo MF. A conduta geral deve ser de verdade e de responsabilidade para com o próprio e para com a sociedade. Uma eventual condenação permitiria um reconhecimento social do incesto e da sua não impunidade e permitiria ao agressor a oportunidade de refletir sobre a sua atuação e, ao mesmo tempo, afastá-lo da vítima ou de potenciais vítimas.

- Discutir os benefícios e desvantagens em referenciar para uma consulta de psicologia/psiquiatria. O processo psicoterapêutico pode ser abordado de modo seguro e controlado, em várias consultas, sabendo que o "ponto de viragem para o doente ocorre quando a sua raiva é experimentada não no vazio, mas como uma resposta adaptativa de sobrevivência à crueldade passada". ${ }^{21}$

- Promover a frequência de reuniões de vítimas de incesto/violência doméstica. Nesta terapia grupal, consistindo num espaço sem julgamentos e de respeito mútuo, a utente poderá encontrar oportunidades de partilha, reconhecer situações e emoções vivenciadas e entender a sua conexão com o abuso. ${ }^{22}$

\section{Oportunidades perdidas, sistema atual e sugestões futuras}

Ao longo da infância e da adolescência existiram alguns contextos (o sistema de saúde, a escola, a ação social, a sociedade) onde alguém mais observador poderia ter feito a diferença.

Há cerca de 30 anos, a medicina era essencialmente 
centrada no médico. Este facto, a par do desconhecimento médico geral da problemática, contribuiu para uma falha diagnóstica. No âmbito da saúde infantil e juvenil nos cuidados de saúde primários (CSP), quando ocorrem dificuldades escolares e de comportamento importantes, a avaliação familiar é mandatória. A vítima em criança deveria ter tido um acompanhamento por psicólogo e assistente social com visitação domiciliária obrigatória.

Na atualidade, os MF têm o direito e a obrigação de sinalizar ( $\operatorname{art}^{\circ} 4^{\circ}$ e $\left.65^{\circ}\right)^{8,11}$ todo o caso de suspeito de maus tratos. De facto, trata-se de um problema específico e complexo que deverá ser referenciado. Desde a criação dos NPCJ em 2007-2008, ${ }^{9}$ o procedimento para com as vítimas menores de idade é de referenciar para o NPCJ local ou, em caso de não resolução, para a CPCJ. ${ }^{11}$ Se for necessária uma intervenção mais imediata serão chamadas as autoridades policiais ou, estando a criança acompanhada com alguém de confiança, é referenciada para um Serviço de Urgência central com possibilidade de realizar perícias legais. Depois de notificado o Ministério Público, este determinará se a intervenção será feita em meio natural de vida (na própria casa) ou se serão instauradas medidas de colocação (colocação em centros de acolhimento, adoção). ${ }^{11}$

Os MF confrontam-se frequentemente com dúvidas de atuação, por exemplo, quando testemunham violência na consulta ou por conhecimento indireto de maus tratos, preferindo muitas vezes não atuar. As barreiras identificadas pelos profissionais que mais impedem o correto encaminhamento da situação passam pelo desconhecimento dos circuitos de referenciação, pelo receio da quebra de sigilo profissional pelas instituições, pela impunidade e pelo descrédito na lei e nas instituições.

As NPCJ/ CPCJ poderão promover a intercolaboração com os MF, por exemplo, através de uma medida tão simples como a troca de mensagens eletrónicas, garantindo-se o conhecimento da estrutura para futuras referenciações e o bom funcionamento da comunicação.

Desde 2013 que o programa informático de saúde infantil realça a pesquisa de violência e maus tratos em todas as idades-chave, a partir do nascimento, no separador Avaliação do risco familiar. Este item ainda não está completamente explorado do ponto de vista do utilizador; quando o for, poderá ser estudada a sua eficácia na deteção de maus-tratos.

Ao nível científico, a violência intrafamiliar é um campo com grandes lacunas. São necessários estudos de incidência, de prevalência e de eficácia sobre métodos de diagnóstico, bem como a construção de protocolos terapêuticos e sua análise.

Nunca é demais realçar que a revelação de abuso efetuada por uma criança é independente dos recursos tecnológicos, pois só ocorrerá com uma figura de confiança. Para isso é necessária, da parte do profissional, uma atitude de disponibilidade constante nos sucessivos contactos. Por norma, o circuito não se inicia nos CSP, começa por um familiar próximo ou um professor na escola que de seguida contacta os serviços de saúde ou as instituições policiais.

Como é na escola o local onde a criança passa mais tempo fora de casa, será este o palco ideal para a sua observação, por exemplo, no pátio enquanto brinca, pela análise dos desenhos e das composições textuais, pela comparação interpares do desenvolvimento, pela observação da interação com a família. Nos dias de hoje, o professor que se aperceba de um aluno "diferente" já tem mais facilidade em referenciar para um psicólogo, para o MF ou em participar em reuniões de pedopsiquiatria.

Num futuro próximo poderá existir um sistema informático que congregue as situações de risco a nível escolar, social e clínico que permita uma abordagem articulada. O sistema deve permitir detetar e convocar crianças que não recorrem ao centro de saúde, que mudam de residência ou que faltem à escola. Sobre o tema da violência poderão existir mais programas de formação ao dispor dos diferentes profissionais (MF, professores, auxiliares de ação educativa) e, para promover a comunicação interprofissional, poderão ser marcadas reuniões conjuntas sobre o tema.

Em relação à sociedade - vizinhos, as agências de adoção, eventualmente a maternidade -, intervieram providenciando um ambiente provavelmente mais seguro para a criança, mas desagregando a família. Duas das crianças nunca conhecerão os seus pais biológicos - não será esta uma forma de agressão? Por outro lado, como foi este o caso, a família adotante consegue continuar a providenciar educação e segurança, apesar do 
contacto e da interferência da família biológica? Um apoio de tipo estrutural - apoio escolar, emprego, aconselhamento parental, etc. - teria tido resultados na dinâmica familiar e com menores custos globais? No futuro poderá existir uma formação parental básica obrigatória para todos os novos pais.

\section{REFERÊNCIAS BIBLIOGRÁFICAS}

1. Hillberg $T$, Hamilton-Giachritsis C, Dixon L. Review of meta-analyses on the association between child sexual abuse and adult mental health difficulties: a systematic approach. Trauma Violence Abuse. 2011;12(1):38-49.

2. O'Leary P, Coohey C, Easton SD. The effect of severe child sexual abuse and disclosure. J Child Sex Abus. 2010;19(3):275-89.

3. Organisation Mondiale de la Santé. Rapport mondial sur la violence et la santé. Genève: OMS; 2002.

4. Barth J, Bermetz L, Heim E, Trelle S, Tonia T. The current prevalence of child sexual abuse worldwide: a systematic review and meta-analysis. Int J Public Health. 2013;58(3):469-83.

5. Zambon MP, Jacintho AC, Medeiros MM, Guglielminetti R, Marmo DB. Violência doméstica contra crianças e adolescentes: um desafio [Domestic violence against children and adolescents: a challenge]. Rev Assoc Med Bras. 2012;58(4):465-71. Portuguese

6. Fávero M. Sexualidade infantil e abusos sexuais a menores. Lisboa: Climepsi; 2003. ISBN 9789727960866

7. Lei $n^{\circ}$ 147/99, de 1 de setembro. Diário da República. $1^{a}$ série-A(204).

8. Prazeres $V$, Jorge $A$, Leça $A$, Perdigão A, Laranjeira AR, Menezes $B$, et al. Crianças e jovens em risco: projecto de intervenção nos serviços de saúde. Lisboa: Direção-Geral da Saúde; 2007.

9. Carvalho R, Alvarez D, Santos L, Bandeira N. Relatório anual de avaliação das atividades das comissões de proteção das crianças e jovens - 2012. Lisboa: Comissão Nacional de Proteção das Crianças e Jovens em Risco; 2013.

10. WONCA. Classificação internacional de cuidados de saúde primários - ICPC2. Revised 2a ed. Lisboa: ACSS; 2011.

11. Meneses $B$, ed. Maus tratos em crianças e jovens: guia prático de abordagem, diagnóstico e intervenção. Lisboa: Direção-Geral da Saúde; 2011.

12. Johnson MS. Recognizing the incestuous family. J Natl Med Assoc. 1983;75(8):757-61.

13. Comisión de No Violencia de la Federación Coordinadora Nicaraguense de la Niñez y la Adolescencia. Así piensan y actuán los abusadores y explotadores sexuales: una visión masculina de la violencia sexual [They think this way and the abusive ones and sexual exploiters act: a masculine vision of the sexual violence]. Managua: CODENI; INPRHU;Asociación La Amistad; 2005. Spanish

14. Brunette B. Sibling incest and guidelines for family treatment. Chicago: UIC; 2001. Available from: www.uic.edu/classes/socw/socw517/siblingincestbrunnette.htm

15. Furniss T.Abuso sexual da criança: uma abordagem multidisciplinar. Porto Alegre: Artes Médicas; 1993. ISBN 8573078634

16. American Psychiatric Association. Diagnostic and statistical manual of mental disorders - DSM-5. 5th ed. Arlington, VA: American Psychiatric Association; 2013. ISBN 9780890425541

17. Fossati A, Madeddu F, Maffei C. Borderline personality disorder and childhood sexual abuse: a meta-analytic study. J Pers Disord. 1999;13(3):268-80.

18. Collin-Vézina D, Daigneault I, Hébert M. Lessons learned from child sexual abuse research: prevalence, outcomes, and preventive strategies. Child Adolesc Psychiatry Ment Health. 2013;7:22.

19. Nelson HD, Selph SS, Gougatsos C, Blazina I. Behavioral interventions and counseling to prevent abuse and neglect: systematic review to update the U.S. preventive services task force recommendation. Rockville, MD: Agency for Healthcare Research and Quality; 2013.

20. Schachter CL, Radomsky NA, Stalker CA, Teram E. Women survivors of child sexual abuse. How can health professionals promote healing? Can Fam Physician. 2004;50:405-12.

21. Internet FAQ Archives. Information about incest. [cited 2013 Nov 25]. Available from: http://www.faqs.org/health/topics/68/Incest.html

22. Brown D, Reyes S, Brown B, Gonzenbach M. The effectiveness of group treatment for female adult incest survivors. J Child Sex Abus. 2013;22(2):143-52.

22. Brown D, Reyes S, Brown B, Gonzenbach M. The effectiveness of group treatment for female adult incest survivors. J Child Sex Abus. 2013;22(2):143-52.

\section{CONFLITOS DE INTERESSE}

A autora declara não ter conflito de interesses.

\section{ENDEREÇO PARA CORRESPONDÊNCIA}

Cristina Correia Romão Ribeiro Nunes

Alameda da Encarnação 11, 1800-187 Lisboa

ccrrn@hotmail.com

Recebido em 17-02-2014

Aceite para publicação em 18-11-2014 


\section{ABSTRACT}

\section{THE PROCESS OF DISCLOSURE: A CASE OF INCEST}

Incest is a public health problem with low visibility. It is under diagnosed by health services. It is often unreported. Conviction rates are low because disclosure by the victim is essential and is rare and difficult. The family physician is in a privileged position to approach this issue.

This case report describes a 39 year old woman who was raised by a foster family from 6 months of age until the age of 7 . She maintained contact with her biological family and was the victim of incest by her older brother until she was 17 . This case describes the lengthy process of disclosure and the associated legal and ethical issues. The patient demonstrated borderline personality disorder, post-traumatic stress disorder, and family and social dysfunction.

Therapy in these cases is prolonged, multidisciplinary and comprehensive, including individual and family therapy. The family physician may adopt an empathic attitude, allowing the patient to recognize that their maladaptative emotions are a survival response to incest in the past.

Keywords: Incest; Violence. 